\title{
Highly efficient and chemoselective synthetic route to de thiazolidinones via a microwave
}

assisted, three component reaction.

Romina A. Ocampo, ${ }^{\text {a }}$ Liliana C. Koll, ${ }^{a}$ Mirta Fascio, ${ }^{b}$ Sandra D. Mandolesi, ${ }^{a}$ Norma B. D'Accorso. ${ }^{* b}$

a Instituto de Química del Sur (INQUISUR-CONICET), Departamento de Química, Universidad Nacional del Sur, Avenida Alem 1253, 8000 Bahía Blanca, Argentina. E-mail: rocampo@uns.edu.ar.

${ }^{b}$ Centro de Investigaciones en Hidratos de Carbono (CIHIDECAR-CONICET), Departamento de Química Orgánica, FCEN, UBA, Intendente Guiraldes 2160, Ciudad Universitaria, C1428EGA Buenos Aires, Argentina. E-mail: norma@qo.fcen.uba.ar.

\section{Abstract:}

We present here the study of selective synthesis of 1,3-thiazolidin-4-ones via microwave-assisted multi-component reaction under solvent-free conditions. Although, theoretically two different products are possible (benzothiazepinones $\mathbf{4}$ and thiazolidinones $\mathbf{5}$ ), the reaction gave only two diasteroisomers of 1,3-thiazolidin-4-ones (48-97\%) in the threecomponent reaction between 2,3 : 4,5-di-O-isopropiliden- $\beta$-D-arabino-hexos-2-ulo-2,6piranosa 1, different heteroaromatics anilines $\mathbf{3}$ and mercaptoacetic acid $\mathbf{2}$ as can be seen in the scheme of Figure 1 . The synthesized compounds were characterized by IR, ${ }^{1} \mathrm{H}-,{ }^{13} \mathrm{C}$, DEPT and HSQC - RMN. The stereochemistry of both the diasteroisomers was elucidated with the help of NOE experiments.

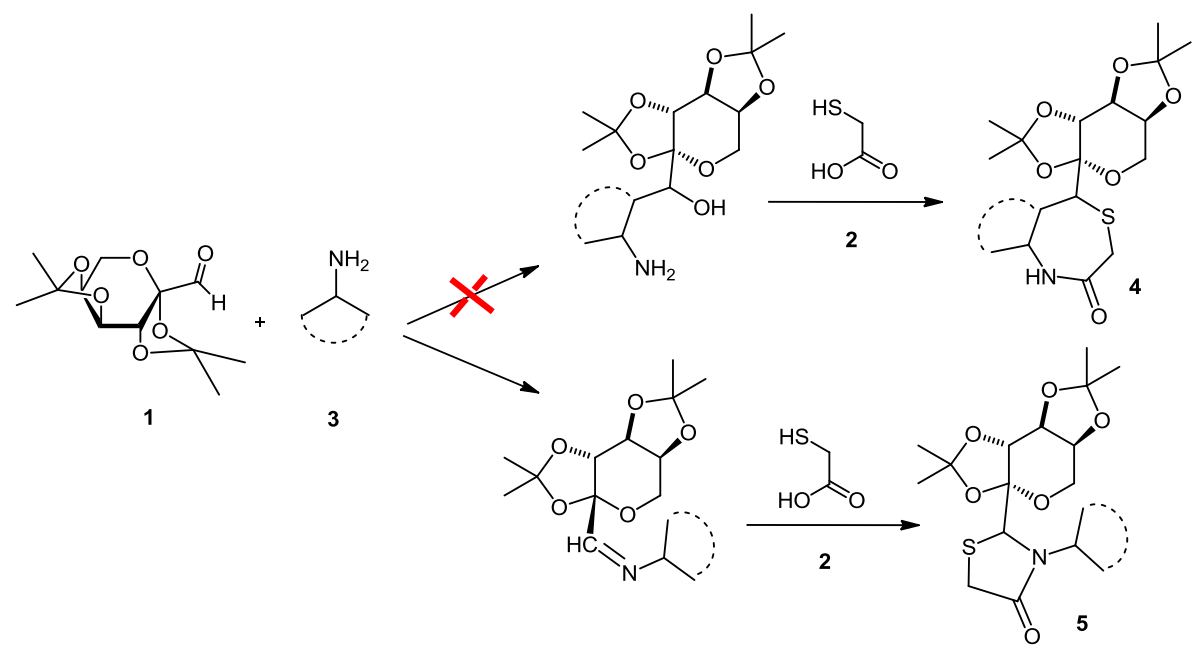

Figure 1

Keywords: Thiazolidinones, chemoselective synthesis, multicomponent reaction. 


\section{Introduction}

Microwave irradiation is an alternative heating method based on the ability of some compounds to transform electromagnetic energy into heat. This method, which increases chemical reaction rates and forms cleaner products, can be successfully applied in pharmaceutical chemistry. ${ }^{1}$ Microwave irradiation reactions has been extended to almost all areas of chemistry with the exception of the carbohydrate chemistry which has suffered a certain delay, as it is testified by the small number of applications.

However, a limited number of these reactions regard so far the carbohydrate chemistry and since carbohydrates play an important role in a vast array of biological processes, and particularly there are many advantages, for example, in carbohydrate-based drugs such as low toxicity and immunogenicity, the interest in their preparation and reactivity by microwave heating is very high.

The 4-thiazolidinones and correlated derivatives have high biological relevance since they are present in both natural products and pharmaceutical compounds. The presence of $\mathrm{N}$ C-S linkage in the compounds has been shown to have hypnotic, ${ }^{2}$ anti-cancer, ${ }^{3}$ cardiovascular, ${ }^{4}$ antioxidant, $^{5} \quad$ anti-inflamatory, $^{6} \quad$ antitubercular, $^{7}$ antihistaminic, ${ }^{8}$ antimicrobial, ${ }^{9}$ anticonvulsant, ${ }^{10}$ antiviral and anti-HIV ${ }^{11}$ acivities. Besides, carbazole, pyrazole and tiazole skeletons constitute the structural core element of many natural and synthesized products. Also show diverse pharmacological properties as exemplified by antitumor, ${ }^{12}$ antimicrobial, ${ }^{13}$ insecticidal, ${ }^{14}$ and anti-inflamatory ${ }^{15}$ activities.

Taking into account these facts and based on the versatile bioactivities of the above mentioned structures, it is promising that the integration of heteroaromatic amines, with carbohydrate scaffold and 4-thiazolidinone segment might result in the discovery of new drug candidates with unknown or enhanced bioactivities.

In the present paper, 4-thiazolidinones (5) have been synthesized by one pot microwave-assisted multicomponent reaction, under solvent-free condition, of 2,3:4,5-di-Oisopropylidene- $\beta$-D-arabino-hexos-2-ulo-2,6-pyranose (1), mercaptoacetic acid (2) and various heteroaromatic amines (3) (Figure 1). 


\section{Results and Discussions}

In order to find suitable conditions for efficient microwave-assisted formation of the 4thiazolidinones we study the reaction of benzaldehyde, aniline and mercaptoacetic acid (1:1:1). Table 1

We started the studies using two different modes of microwave irradiation: Standard Control and SPS Control. These options permit the user to control how the system applies the microwave energy to the reaction. The Standar Control option provides more flexibility in how the user program a reaction method and makes greater use of the feedback control data from the temperature and pressure systems. It applies a specified amount of power, defined by the use, to reach the control point. It modulates this set power automatically, based on the sensor feedback data, to ensure the control point is reached rapidly, but with limited error.

The SPS Control option will irradiate at the defined power to bring the reaction mixture to the control temperature and then generates cycles of power on and off for the remainder of the run time as the temperature varies between the control temperature and a user defined deviation - usually $5^{\circ} \mathrm{C}$ below the control temperature.

Under these last conditions and varying the power and temperature, in either case the compound of interest was obtained with acceptable yields, generating an inorganic residue (solid black, insoluble in acetone and ethanol, soluble in DMSO, with no signals of ${ }^{1} \mathrm{H}$ - and ${ }^{13} \mathrm{C}$ NMR) probably due to the charring of the reactants or the product.

Fortunately, when the reaction was carried out using the Standard Control under 300 W power microwave irradiation at $120^{\circ} \mathrm{C}$ it afforded the 4-thiazolidinone (5) with excellent yields. The sample is irradiated by consecutive periods of 5 minutes with addition of further amounts of mercaptoacetic acid at 5 and 10 minutes of irradiation due to its volatility (bp: 96 ${ }^{\circ} \mathrm{C}$ ). The GC-MS of the aliquots taken at 5 and 10 minutes show large proportion of the imine (reaction intermediate I), while the aliquot taken at 15 minutes of reaction allows to see the reaction intermediate consumption and product $\mathbf{5}$ formation. After $15 \mathrm{~min}$ of reaction under microwave conditions, no progress in the reaction was seen by TLC analysis (Figure 2). 

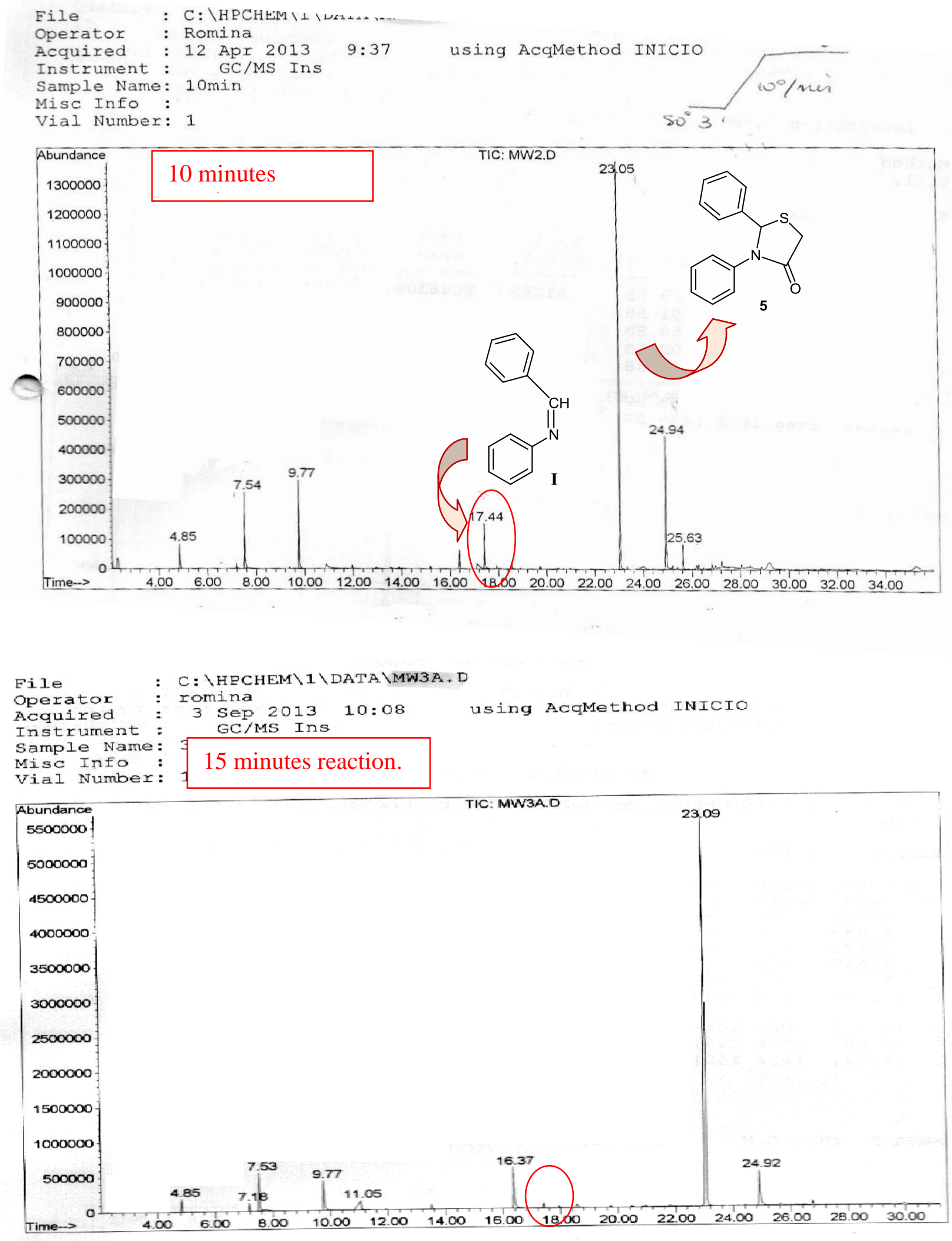

Figure 2 
Data obtained with each method using $120^{\circ} \mathrm{C}$ temperature and powers ranging between 200 and 300W for the stated reaction were tabulated in Table 1.

Table 1.

\begin{tabular}{ccccc}
\hline Entry & Power (W) & Time (min.) & \multicolumn{2}{c}{ Yield (\%) $^{\text {a }}$} \\
& & & SPS control & Standard $^{\text {b }}$ \\
\hline $\mathbf{1}$ & 200 & 5 & 18 & 24 \\
$\mathbf{3}$ & 200 & 10 & 23 & 27 \\
\hline $\mathbf{4}$ & 200 & 15 & 32 & 53 \\
$\mathbf{5}$ & 250 & 5 & 19 & 30 \\
$\mathbf{6}$ & 250 & 10 & 26 & 39 \\
$\mathbf{7}$ & 250 & 15 & 31 & 63 \\
$\mathbf{8}$ & 300 & 5 & 17 & 32 \\
$\mathbf{9}$ & 300 & 10 & 31 & 58 \\
\hline
\end{tabular}

a Determined by CG-MS analysis of crude reaction through a standard curve generated from isolated pure product.

${ }^{\mathbf{b}}$ Temperature and power selected in the microwave apparatus

As shown in Table 1, the best conditions of temperature and power to these solvent free multicomponent reactions is the Standard Control, using irradiation at $\mathrm{T}^{\circ}: 120^{\circ} \mathrm{C}$, power: $300 \mathrm{~W}$ (entry 9).

Given the optimal reaction conditions, we began the studies using 2,3: 4,5-di-Oisopropylidene- $\beta$-D-arabino-hexos-2-ulo-2,6-pyranose (1) in place of benzaldehyde, using at first the same amine (aniline, 3a), to adjust the reaction conditions when using sugar (Figure 3).

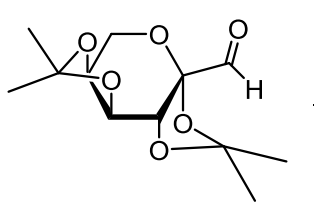

1<smiles>Nc1ccccc1</smiles>

$3 a$<smiles>CC1(C)OC2COC3(/C=N\c4ccccc4)OC(C)(C)OC2[C@H]3O1</smiles>

Ia

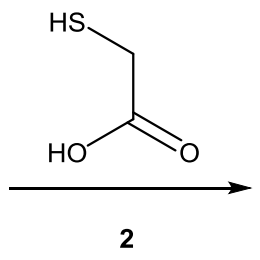

2<smiles>CC1(C)OC2C3O[C@](C4SCC(=O)N4c4ccccc4)(OCC3OC2(C)C)O1</smiles>

$5 a$

Figure 3 
As will be observed later in Table 2, the Standard Condition method of irradiation using $300 \mathrm{~W}$ power and $120^{\circ} \mathrm{C}$ temperature afforded the product $5 \mathrm{a}$ with good yield $(87 \%)$ calculated by GC-MS on an average of three reactions performed under the same conditions (Figure 4a). From the NMR spectra analysis is deduced that the reaction product is a mixture of the two possible diastereoisomers. In this case the GC-MS shows only a broad peak due to the presence of the mixture of diastereoisomers associated to the structures of Figure $\mathbf{4 b}$.

Furthermore, if the GC-MS (Figure 4a) is analyzed it can be observed that the mass fragmentation of the peak with retention time 21.51 minutes correlates with the presence of the reaction intermediate Ia, which confirms the formation of the 4-thiazolidinones associated $5 a$.
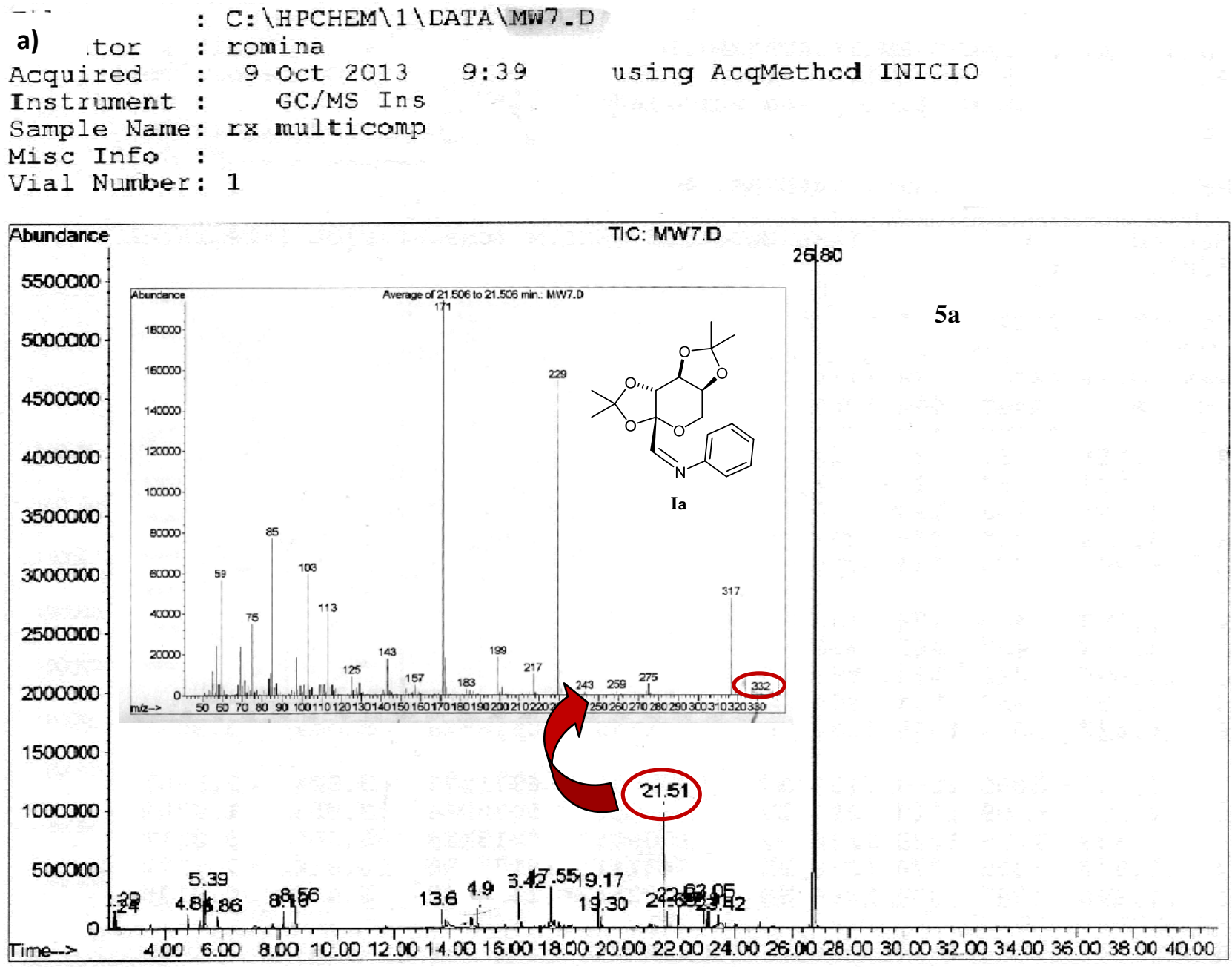


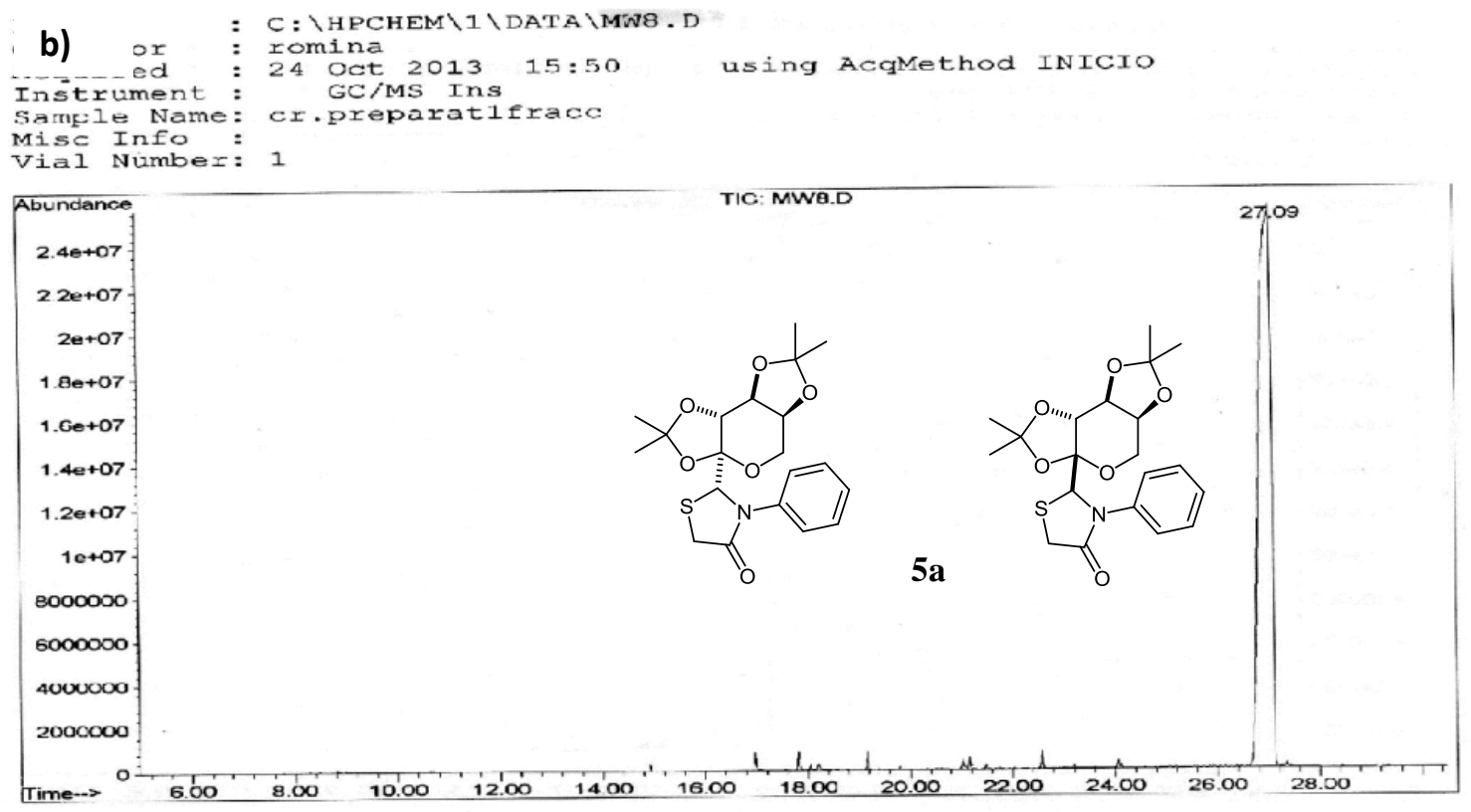

Figure 4

The mixture of diastereomers was isolated by chromatography on neutral alumina column, using as eluent: petroleum ether 60-80 / ethyl acetate (50:50). We could not separate any of them from the mix, even using flash chromatography or preparative TLC. In the ${ }^{1} \mathrm{H}-,{ }^{13} \mathrm{C}$ and DEPT-NMR spectra are observed "duplicated signals", characteristics of the existence of the two isomers (Figure 5).

In the ${ }^{1} \mathrm{H}-\mathrm{NMR}$ spectrum it is not observed the signal corresponding to the $\mathrm{H}$ bonded to $\mathrm{N}$ in the 7-membered ring benzothiazepine (which generally corresponds to a $\delta: 9-13 \mathrm{ppm}){ }^{16}$ This fact, together with the absence of $\mathrm{NH}$ stretching band in the IR spectrum confirms the selective formation of the 4-thiazolidinones as single reaction product.

The area of the $\mathrm{H}$ bonded to the asymmetric carbon produced in the reaction (painted in blue and red in the ${ }^{1} \mathrm{H}-\mathrm{NMR}$ spectrum of Figure 5), allowed to reveal that the mixture of the two diastereomers is in 40:60 ratio. 
${ }^{1} \mathrm{H}-\mathrm{RMN}$

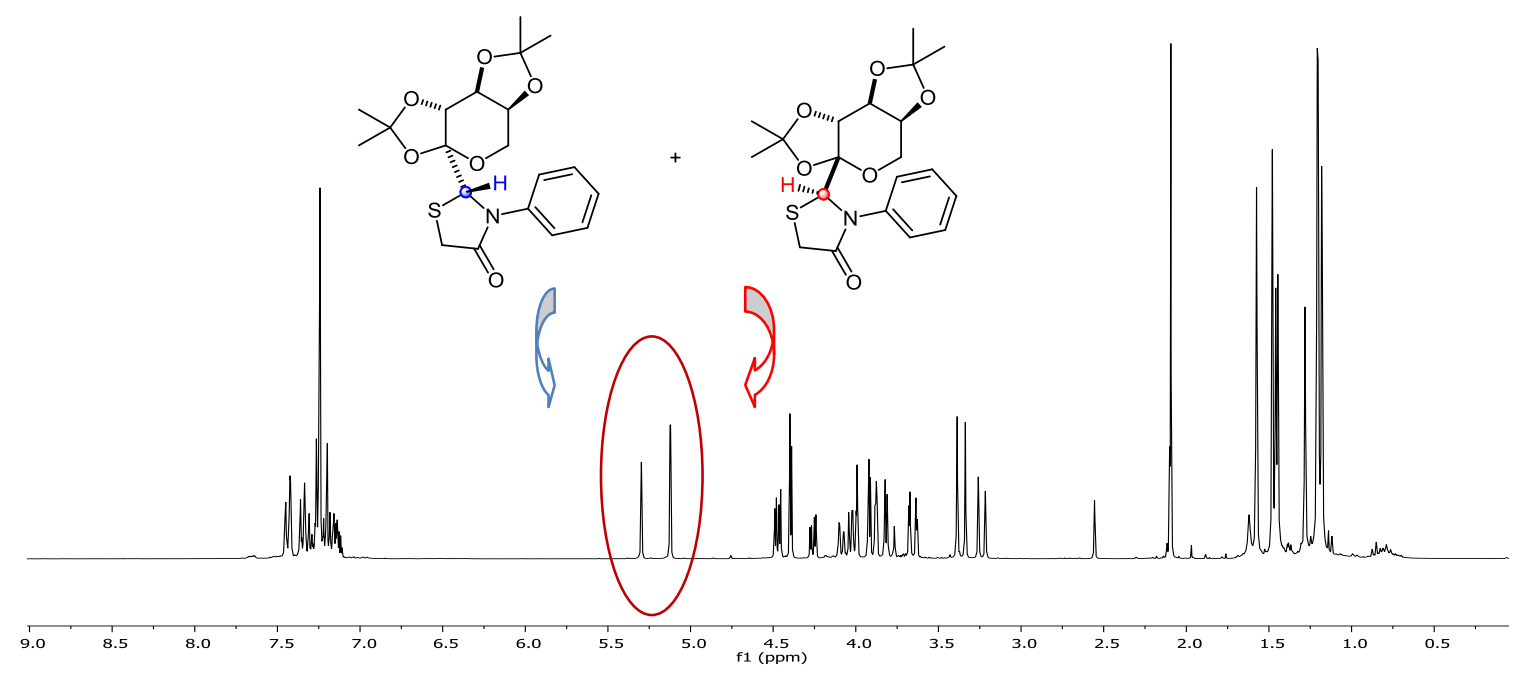

${ }^{13} \mathrm{C}-\mathrm{RMN}$
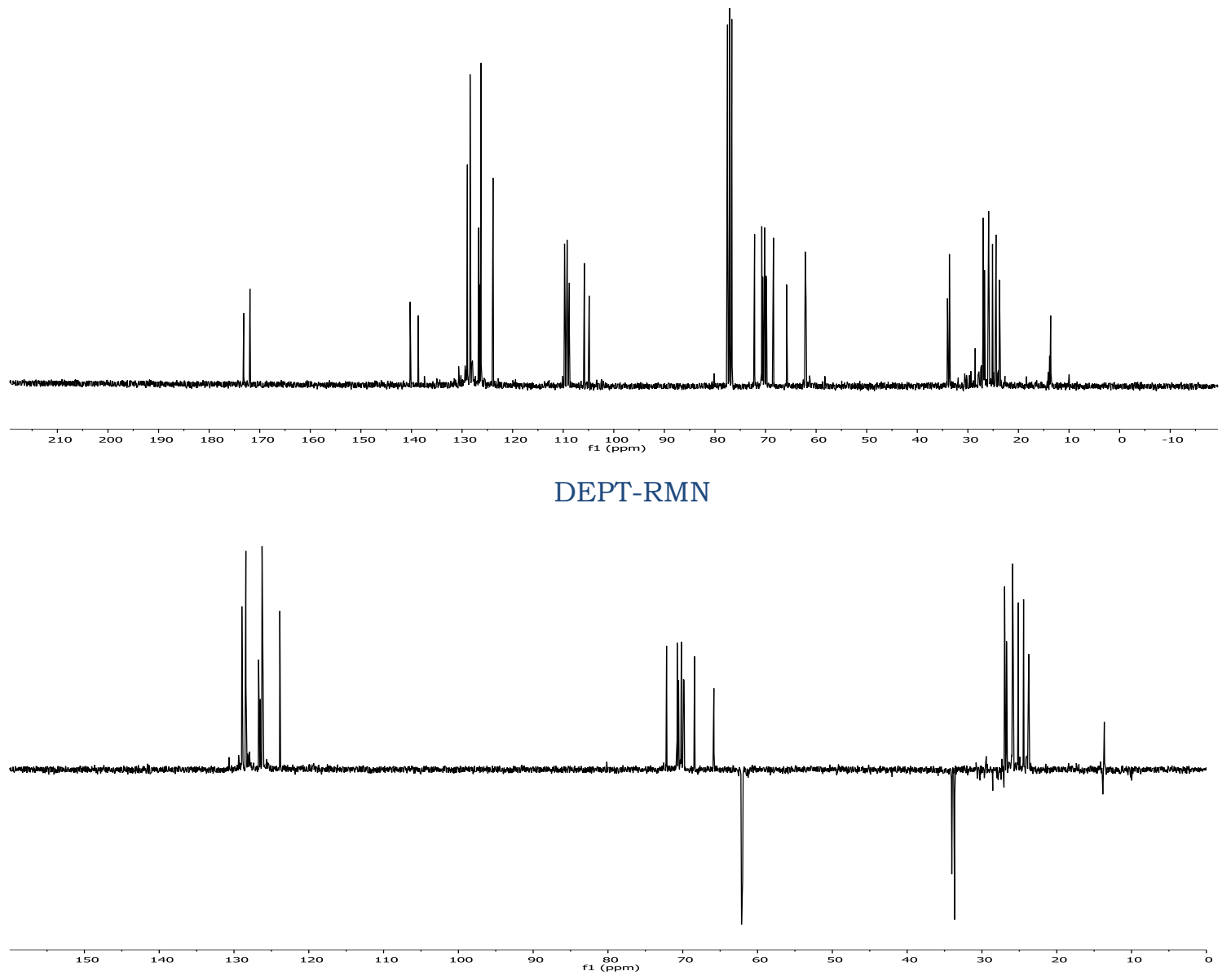

Figure 5 
Based on the previously obtained results, we started the study of the threecomponent reaction under the same microwave conditions established, using various heteroaromatic amines: 3-amino-5-methylpyrazole (3b), 2-aminothiazole (3c), 3 amino-1,2,4triazole (3d), 2-aminobenzothiazole (3e), 3-amino-9-ethylcarbazole (3f), 5-aminouracil (3g) and 3-aminoquinoline (3h). The results obtained with the different amines are summarized in

\section{Table 2.}

Table 2

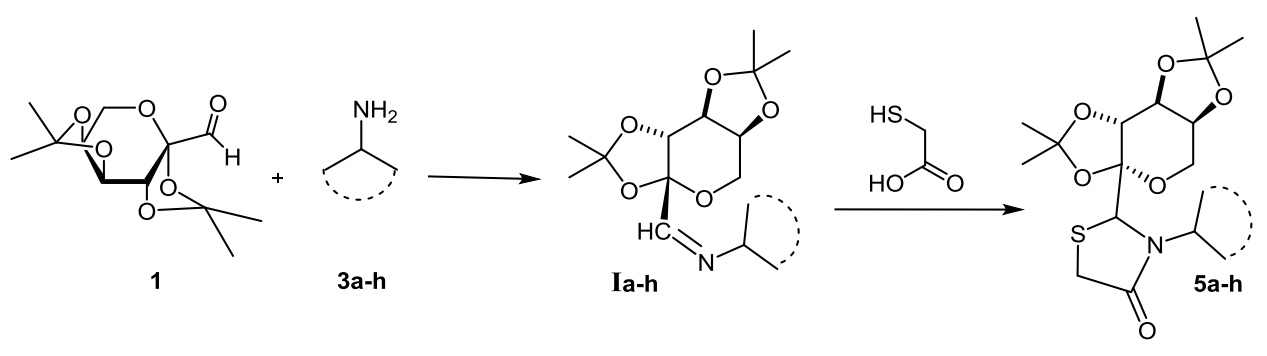

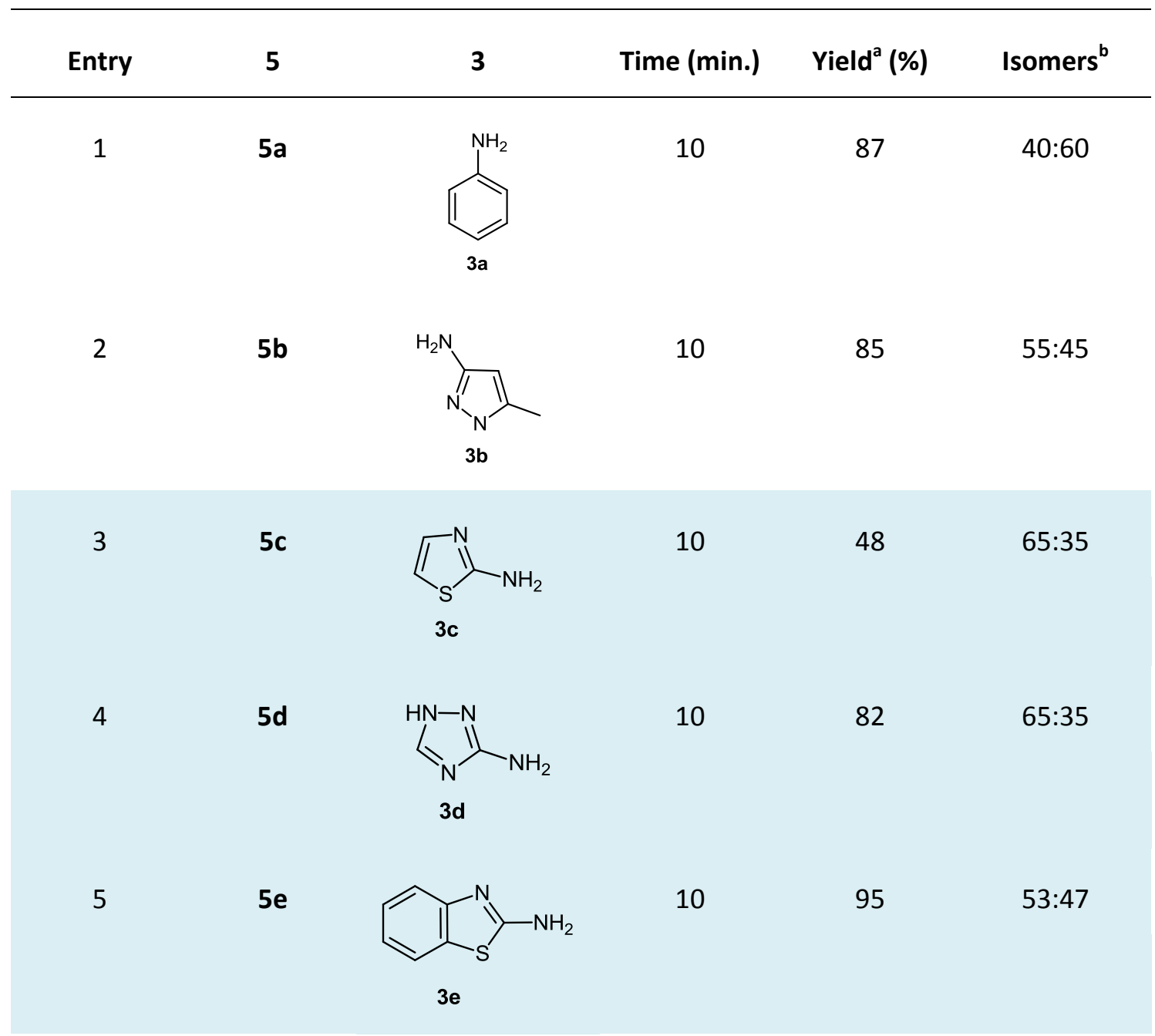


6

$5 f$<smiles>CCn1c2ccccc2c2cc(N)ccc21</smiles>

7

$5 g$<smiles>Nc1c[nH]c(=O)[nH]c1=O</smiles>

$3 g$

8

$5 h$

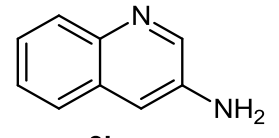

$3 \mathrm{~h}$
10

97

$68: 32$

10

94

$75: 25$

10

89

Isolated yield of diastereomeric mixture.

${ }^{\mathrm{b}}$ Ratio of diastereomers was determined by ${ }^{1} \mathrm{H}-\mathrm{RMN}$.

The products were characterized by $\mathrm{IR},{ }^{1} \mathrm{H}-,{ }^{13} \mathrm{C}$ - and DEPT-NMR spectroscopy, confirming the data obtained by GC-MS.

Is worth highlighting that for the inputs 3, 4 and 5 in Table 2, the heteroaromatic amines used condition the reaction to five-member products formation. In all other cases, the formation of products of 5 to 7 members is feasible, although, as can be seen, only the 4thiazolidinones are selectively obtained.

In most cases $(\mathbf{5 b}, \mathbf{5 c}, \mathbf{5 d}, \mathbf{5 e}, \mathbf{5 f})$ two peaks are observed in the GC with identical fragmentation, corresponding to the two formed diastereoisomers. In all other cases, if only a broad peak is observed in the GC, the NMR spectra confirm the presence of the corresponding diastereoisomeric mixture. The proportion of each in the mixture is calculated using the respective ${ }^{1} \mathrm{H}-\mathrm{NMR}$ spectra.

By using 2-aminobenzothiazole (3e) as heteroaromatic amine (entry 5, Table 2) the mixture of diastereomers is obtained as reaction products. The ${ }^{1} \mathrm{H}-\mathrm{NMR}$ and GC-MS revealed that the mixture of the two diastereoisomers is in ratio 53:47 (Figure 6). 

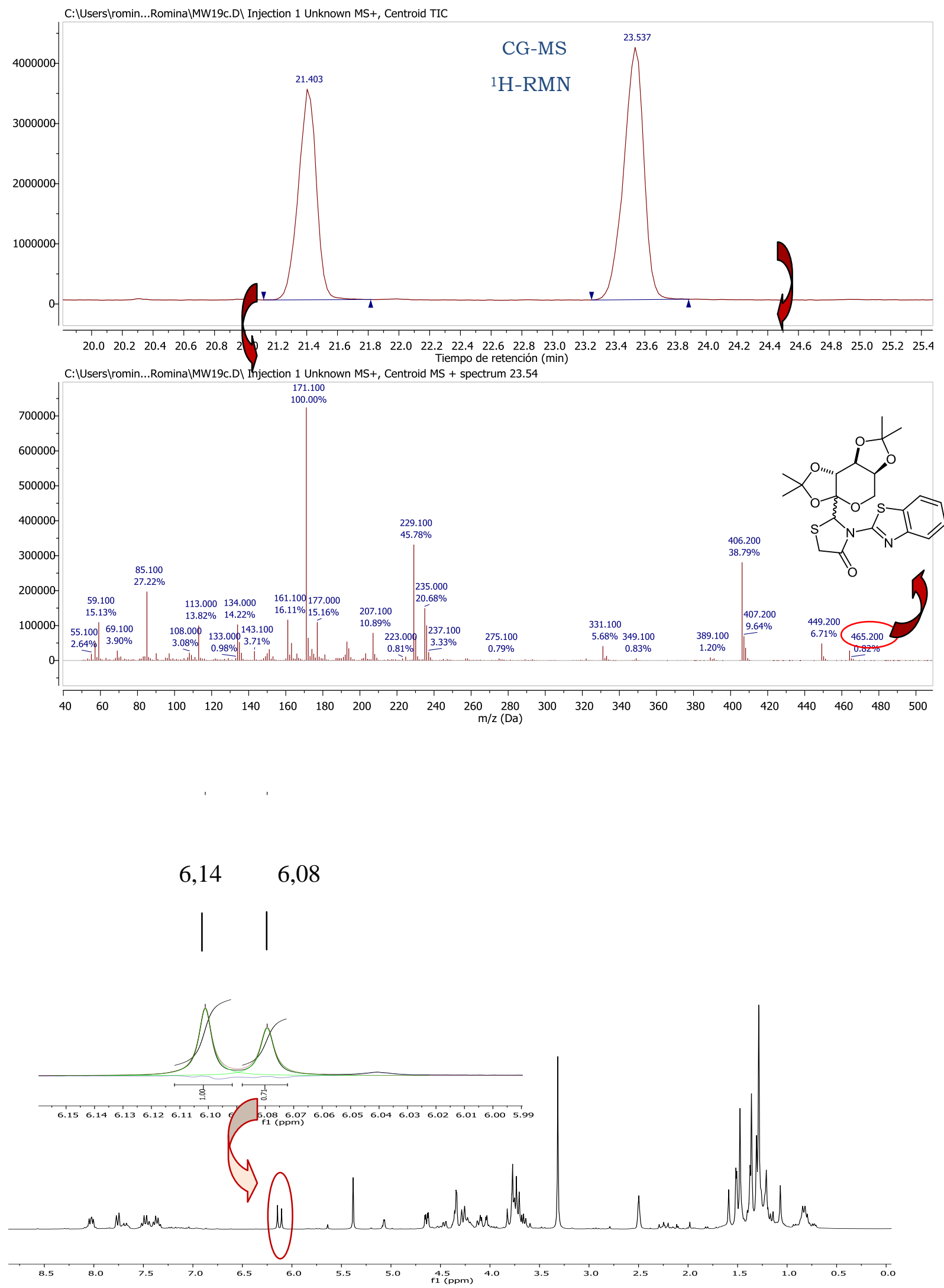

Figure 6 
The crude reaction product was subjected to column chromatography on neutral alumina to separate the isomers without succeeding. Fortunately one of them was isolated by digestion in absolute ethanol. The structure of this diastereomer was determined by ${ }^{1} \mathrm{H},{ }^{13} \mathrm{C}$, DEPT- HSQC- NOESY.2D and 1D selective NOESY - NMR spectroscopy.

Spectroscopic data of ${ }^{1} \mathrm{H}$ and ${ }^{13} \mathrm{C}-\mathrm{NMR}$ are summarized in Figure $\mathbf{7}$ and Table 3.

${ }^{1} \mathrm{H}-\mathrm{RMN}$

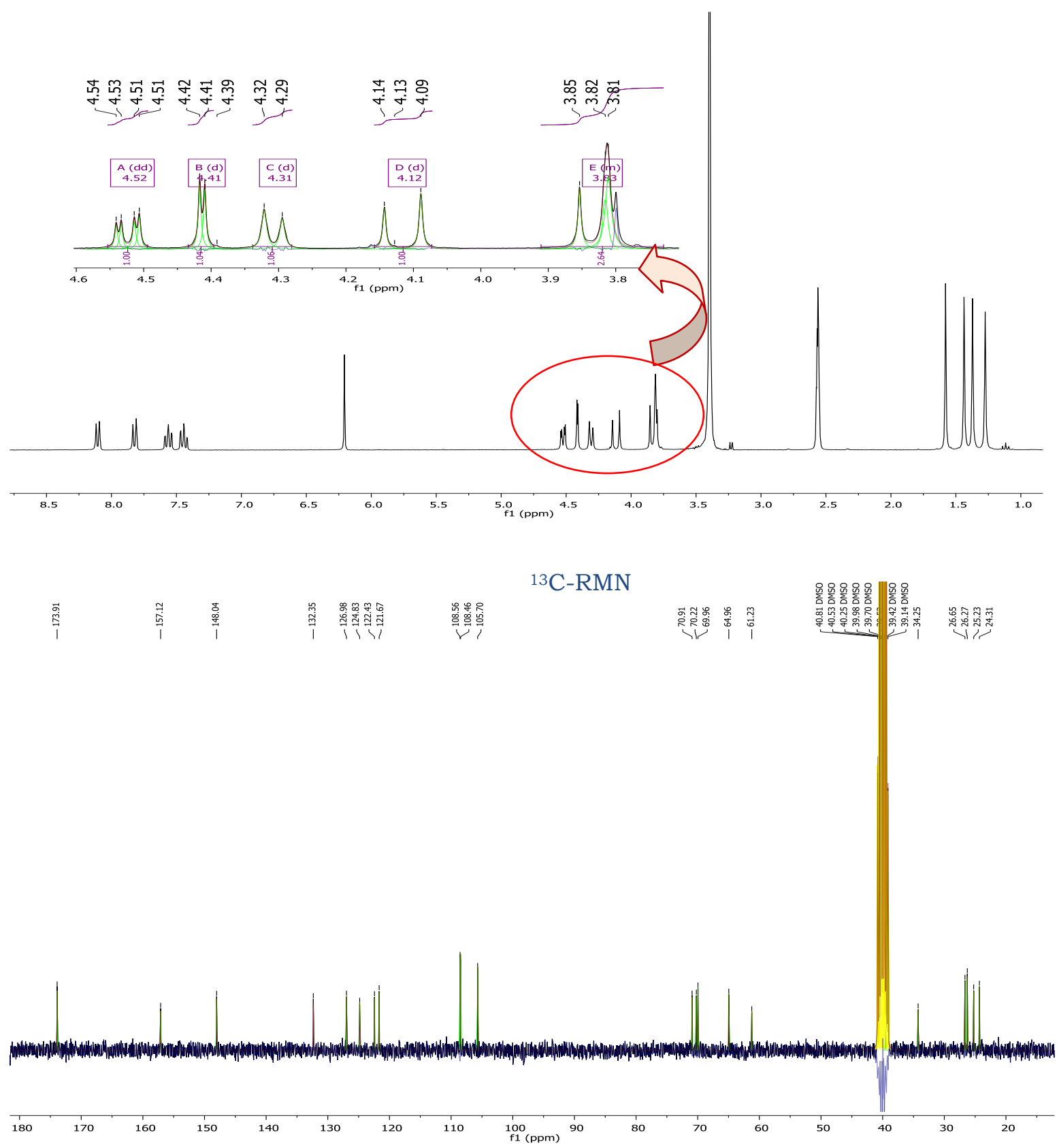




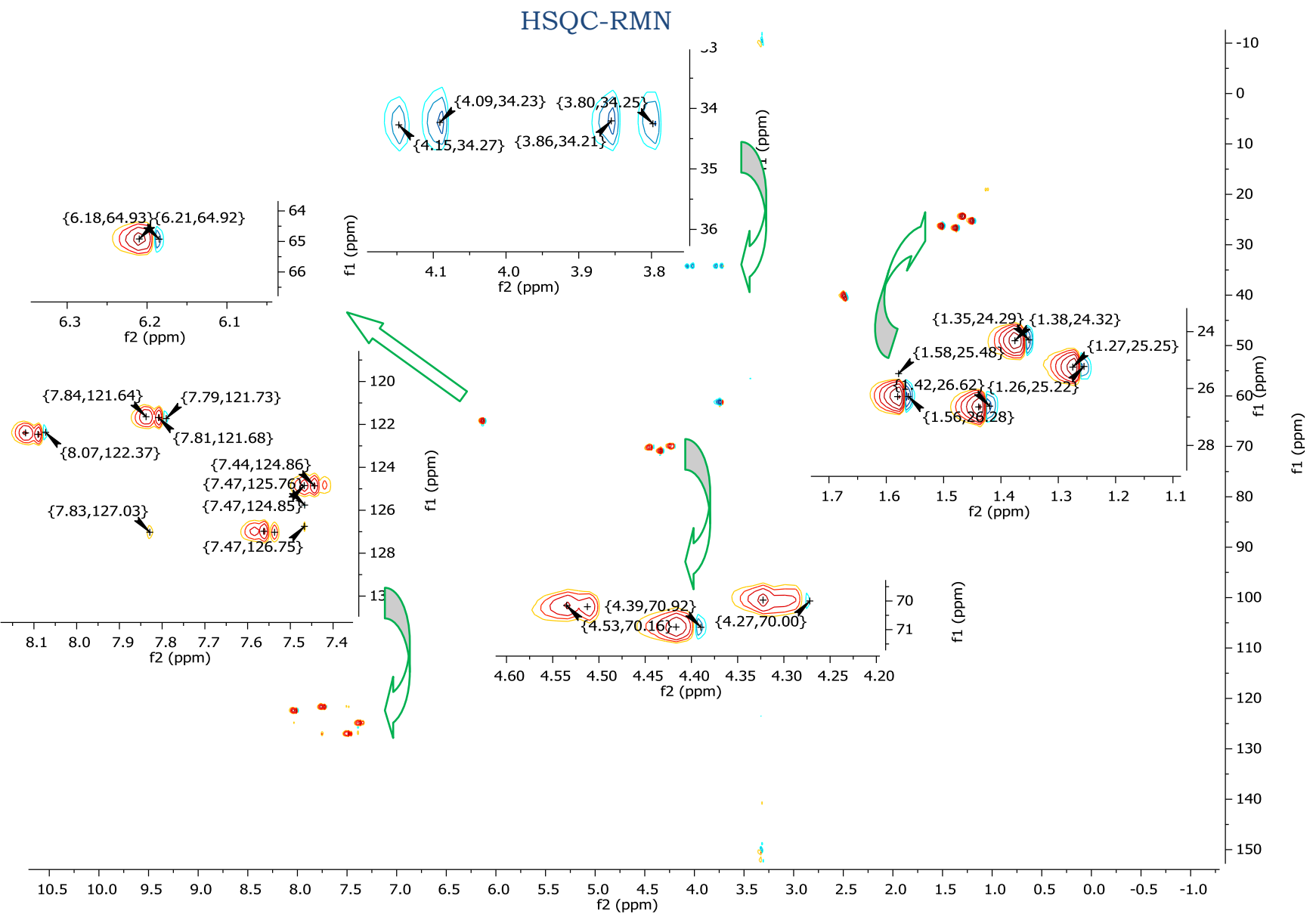

Figure 7

Table 3

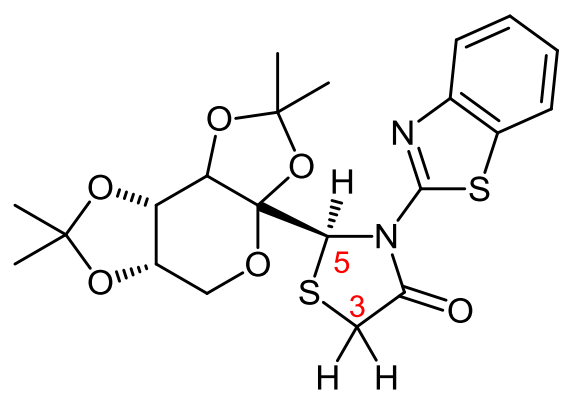

${ }^{1}$ H NMR (300 MHz, DMSO- $\left.d_{6}\right) \delta 8.14-8.07$

$(\mathrm{m}, 1 \mathrm{H}), 7.82(\mathrm{~m}, 1 \mathrm{H}), 7.56(\mathrm{~m}, 1 \mathrm{H}), 7.44(\mathrm{~m}$, $1 \mathrm{H}), 6.21(\mathrm{~s}, 1 \mathrm{H}), 4.52(\mathrm{~d}, J=8.0 \mathrm{~Hz}, 1 \mathrm{H})$, $4.41(\mathrm{~d}, J=2.3 \mathrm{~Hz}, 1 \mathrm{H}), 4.31(\mathrm{~d}, J=8.1 \mathrm{~Hz}$, 1H), 4.12 (d, $J=16.3 \mathrm{~Hz}, 1 \mathrm{H}), 3.82(\mathrm{~d}, J=$ $16.3 \mathrm{~Hz}, 1 \mathrm{H}), 2.56(\mathrm{~m}, 2 \mathrm{H}), 1.58(\mathrm{~s}, 3 \mathrm{H}), 1.44$ $(\mathrm{s}, 3 \mathrm{H}), 1.37(\mathrm{~s}, 3 \mathrm{H}), 1.27(\mathrm{~s}, 3 \mathrm{H})$. 


\footnotetext{
${ }^{13}$ C NMR (75 MHz, DMSO): 173.87, 157.10, $147.97,132.38,126.92,124.92,122.36$, $121.61,108.59,108.40,105.77,70.86$, $70.18,69.92,64.89,61.19,34.30,26.62$, $26.22,25.17,24.26$.
}

From the HSQC spectrum analysis it was determined that the singlet at $6.21 \mathrm{ppm}$ is attached to the new asymmetric $C$ generated in the reaction $\left(C_{5} \delta: 64.89 \mathrm{ppm}\right)$. Furthermore, doublets with $\mathrm{J}=16.3 \mathrm{~Hz}$ and chemical shifts in ppm 4.12 and $3.82 \mathrm{ppm}$ correspond to the protons attached to $C_{3}(\delta 34.30 \mathrm{ppm})$.

The structure of the two diasteroisomers is observed in Figure 8. The stereochemistry of the isolated diastereoisomer was elucidated by NOE experiments. The NOE.2D interactions are discussed in Figure 9.

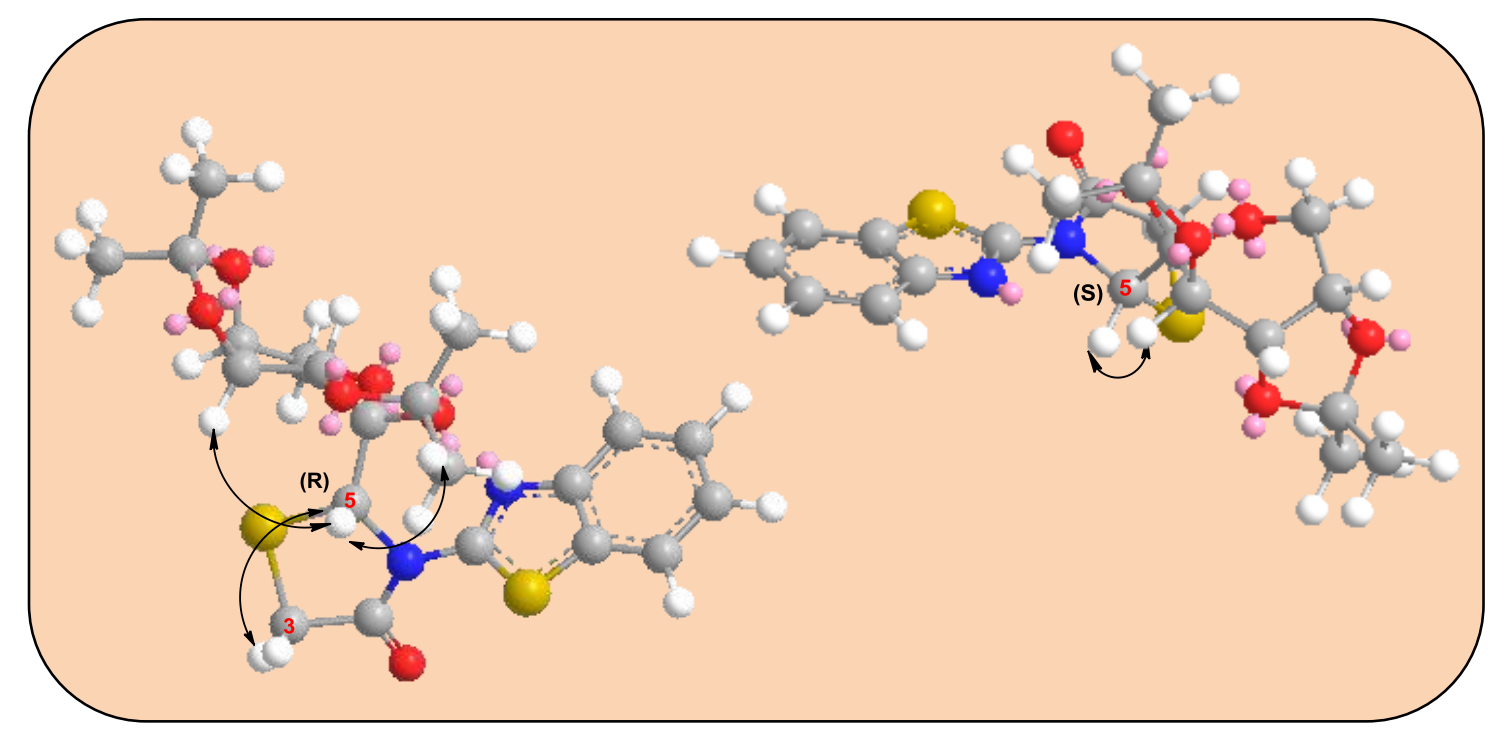

Figure 8

As shown in Figure 8 , in the $(R)$ configuration, the proton bonded to $C_{5}$ shows NOE interaction with $C_{3}$ protons and protons associated with two of the methyl groups of the 2,3-Oisopropyliden sugar structural moieties. Furthermore, and as can be noted in the NOESY spectrum of Figure 9, there is also NOE interaction with the proton of $\delta: 4.41 \mathrm{ppm}$ which is 
associated with the $C$ of $\delta: 70.20 \mathrm{ppm}$ from the pyranose ring. These interactions would be absent in the case of the $(S)$-isomer, in which the only possible interaction would be that shown in Figure 8.

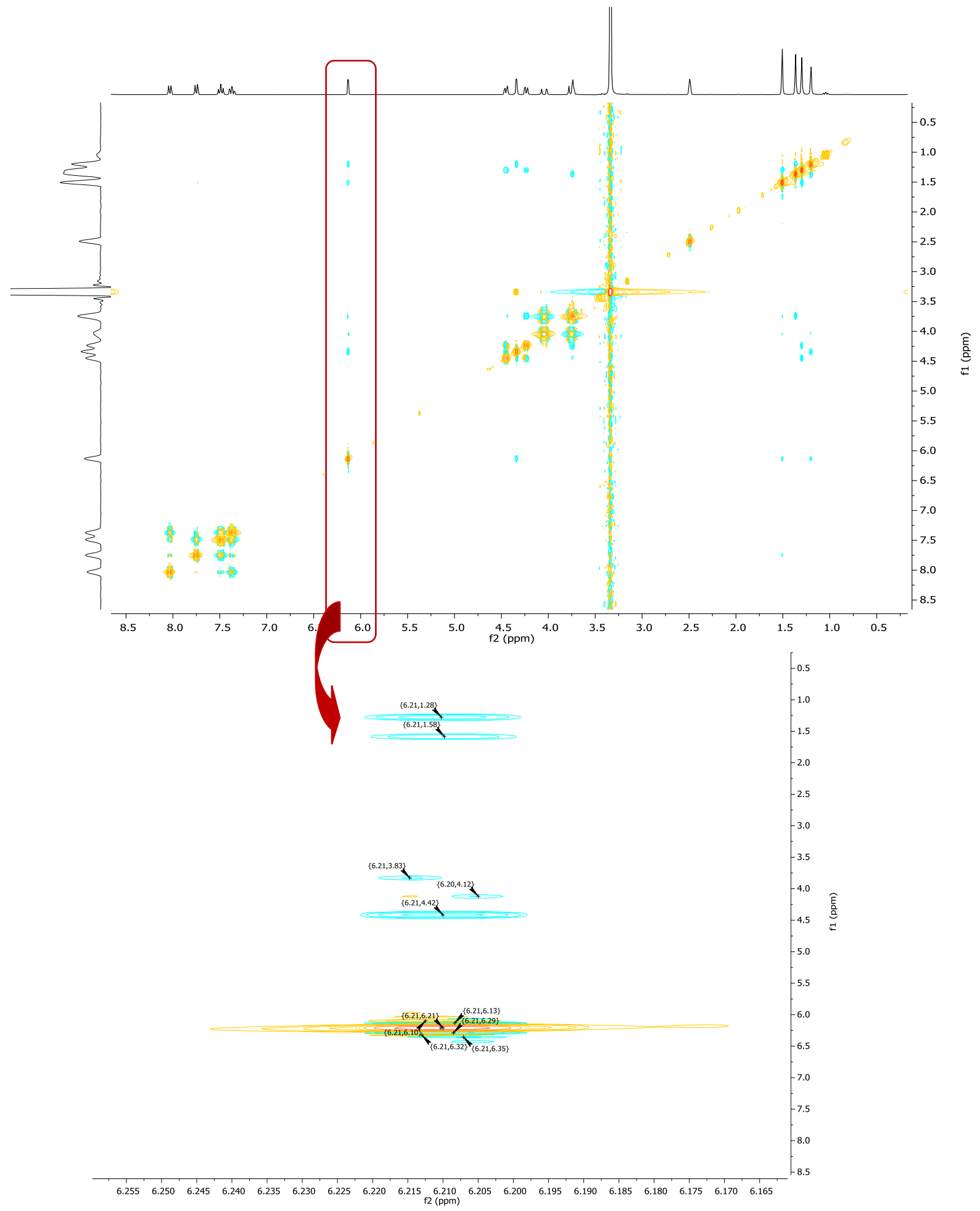

Figure 9 
In the reaction of entry 3, Table 2, the mixture of diastereoisomers is obtained in 65:35 ratio, calculated by ${ }^{1} \mathrm{H}-\mathrm{NMR}$ and GC-MS (Figure 10).

As seen in the table, the yield of the isolated mixture of isomers is far lower than in the other cases (48\%). Furthermore, when analyzing the gas chromatogram it can be noted that it has the particularity of showing two peaks with identical mass fragmentation in the elution region of the reaction intermediate.

Together with the data of the ${ }^{1} \mathrm{H}-,{ }^{13} \mathrm{C}-$, DEPT-NMR spectra and previous literature, ${ }^{17}$ serves to identify it as 1-(2,3: 4,5-di-O-isopropylidene- $\beta$-D-arabino-hexos-2-ulo-2,6-pyranosyl) 1,3-oxathiolan-5-one (6c, Figure 10).

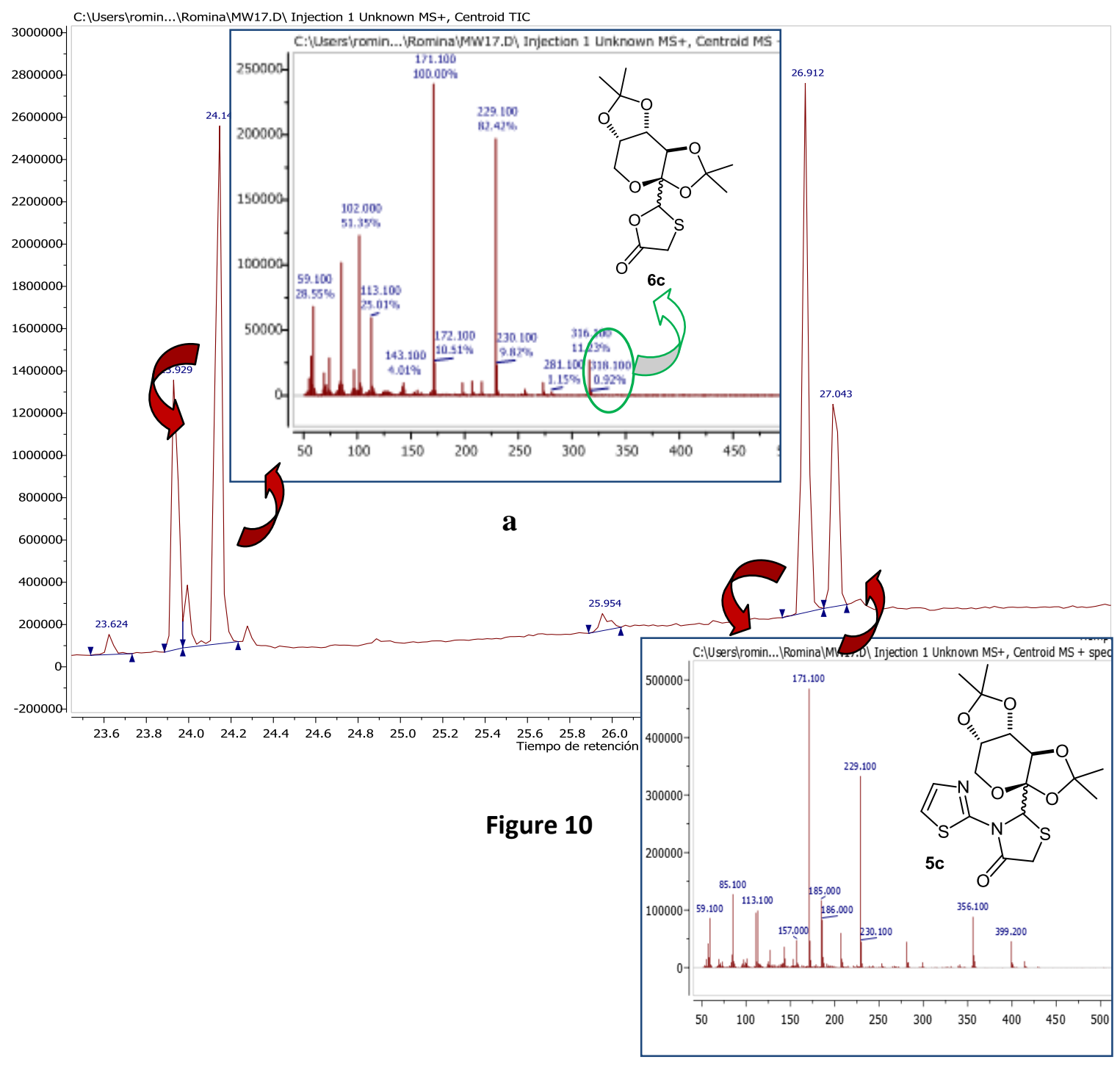


As seen in Figure 10a, the molecular ion is coincident with the molecular weight of the proposed intermediate $\mathbf{6 c}$. Furthermore, in the CG, the two peaks assigned to the intermediate are corresponding to the fact that it has an asymmetric carbon, and hence two possible diastereoisomers.

According to previous studies, the presence of this type of intermediate generated in the reaction mixture suggests that the imine Ic is unstable under the reaction conditions favoring the formation of the oxathiolane. This is consistent with the significant decrease in the yield of the corresponding 4-thiazolidinone $\mathbf{5 c}$.

\section{Conclusions}

A stereoselective synthesis of 4-thiazolidinones from a microwave-assisted multicomponent reaction under solvent-free conditions between $2,3: 4,5$-di-O-isopropiliden- $\beta$-Darabino-hexos-2-ulo-2,6-piranosa, different heteroaromatics anilines and mercaptoacetic acid has been achieved. Although two chiral products are possible (benzothiazepinones and thiazolidinones), only two diastereomers of 4-thiazolidinones were obtained. The reaction is easy to perform using inexpensive starting materials and generates products in moderate to high yields. The one-pot microwave-assisted conditions was shown to be an operational simplicity and environmentally friendly method, in terms of atom economy, energy consumption and time required, to make this new synthetic strategy highly attractive and promising for the access of compounds of potential biological interest. The studies on the purification and characterization of each of the compounds reported here is underway.

\section{Acknowledgments}

This work was supported by grants from ANPCyT (Capital Federal, Argentina), CONICET (Buenos Aires, Argentina) UBA (Universidad de Buenos Aires, Argentina) and UNS (Universidad Nacional del Sur, Bahía Blanca, Argentina). A fellowship from CONICET to RAO is acknowledged. 


\section{Experimental}

\section{General information}

Thin layer chromatography was performed on Merck precoated silica gel 60 F254 plates and visualization was accomplished with UV light and/or 5\% ethanol solution of phosphomolibdic acid. Silica gel (Merck, 230-400 mesh) was used for column chromatography. Melting points were recorded on a Büchi Melting Point B-545 instrument and are uncorrected. Mass spectra were obtained with a GC/MS instrument (HP5-MS capillary column, $30 \mathrm{~m} / 0.25 \mathrm{~mm} / 0.25$ $\mathrm{mm}$ ) equipped with 5972 mass selective detector operating at $70 \mathrm{eV}(\mathrm{EI})$. Infrared spectra were recorded with a Nicolet Nexus 470 FT spectrometer. NMR spectra were recorded in $\mathrm{CDCl}_{3}$ on a $300 \mathrm{MHz}$ spectrometer (300.1 MHz for ${ }^{1} \mathrm{H}$ and $75.5 \mathrm{MHz}$ for ${ }^{13} \mathrm{C}$ ) at 23으. Microwave reactions were performed with a microwave oven (CEM Discover) with a continuous focused microwave power delivery system in a pressure glass vessel $(10 \mathrm{~mL})$ sealed with a septum under magnetic stirring. The reaction mixture temperature was monitored using a calibrated infrared temperature control under the reaction vessel, and control of the pressure was performed with a pressure sensor connected to the septum of the vessel.

The 2,3:4,5-di-O-isopropylidene- $\beta$-D-arabino-hexos-2-ulo-2,6-piranose (1), was prepared according to literature procedure ${ }^{18}$. Compounds described here were characterized by $I R,{ }^{1} \mathrm{H}$, ${ }^{13} \mathrm{C}$, DEPT- NMR confirming the data obtained by GC-MS. Assignments of the ${ }^{1} \mathrm{H}$ and ${ }^{13} \mathrm{C}-\mathrm{NMR}$ spectra were confirmed with the aid of two dimensional techniques ${ }^{1} \mathrm{H},{ }^{13} \mathrm{C}$ (HSQC) and ${ }^{1} \mathrm{H},{ }^{1} \mathrm{H}$ (NOESY). Minimum energy structures were founded with ChemBio3D Ultra 12.0, using MM2 force field.

\section{General methods}

All the reactions were carried out following the same procedure.

A mixture of 2,3:4,5-di-O-isopropylidene- $\beta$-D-arabino-hexos-2-ulo-2,6-piranose $(1,0,242 \mathrm{~g}, 1$ $\mathrm{mmol})$, mercaptoacetic acid $(\mathbf{2}, 0,07 \mathrm{~mL}, 1 \mathrm{mmol})$ and various heteroaromatic amines $(3,1$ $\mathrm{mmol}$ ) were heated in the microwave apparatus at $300 \mathrm{~W}$ and $120^{\circ} \mathrm{C}$ under solvent-free conditions. After 10 min of reaction, no progress in the reaction was seen by TLC analysis. The crude product was analyzed by CG-MS and ${ }^{1} \mathrm{H}-\mathrm{RMN}$. Crude product was purified by recrystallization using ethanol as solvent. 


\section{References}

1. (a) B. L. Hayes, Microwave Synthesis. 2002. (b) Lidstrom, P.; Tierney, J.; Wathey, B.; Westman, J.Tetrahedron, 2001, 57, 9225.

2. S. K. Chaudhary, M. Verma, A. K. Chaturvedi and S. S. Parmar, J. Pharma. Sci., 1975, 64, 614.

3. B. R. Shah, N. C. Desai, N. K. Undavia and P. B. Trivedi, Indian J. Heterocycl. Chem., 1993, 2, 249 ; Chem. Abstr., 1994, 120, 217397r.

4. S. Nagar, H. H. Singh, J. N. Sinha and S. S. Parmar, J. Med. Chem., 1973, 16, 178.

5. T. Kato, T. Ozaki, K. Tamura, Y. Suzuki, M. Akima, N. Ohi, J. Med. Chem., 1998, 41(22), 4309; Chem. Abstr., 1999, 130, 20194x.

6. A. Kumar, C. S. Rajput, Eur J Med Chem., 2009, 44, 83.

7. H. H. Parekh, K. A. Parikh, A. R. Parikh, J Sc Islamic Repub Iran., 2004, 15(2), 143.

8. M. V. Diurno, O. Mazzoni, E. Piscopo, A. Calignano, F. Giordano, A. Bolognesell, J Med Chem., 1992, 35, 2910.

9. (a) V. V. Mulwad, A. A. Mir, H. T. Parmar, Ind J Chem. , 2009, 48B, 137. (b) S. D. Srivastava, J. P. Sen, Ind J Chem., 2008, 47B, 1583. (c) N. K. El-Aasar, K. F. Saied, J Heterocycl Chem., 2008, 45, 645. (d) V. V. Mulwad, S. A. Mayekar, Ind J Chem., 2008, 47B, 1397. (e) S. R. Lokhandwala, K. R. Desai, Phosphorus, Sulfur and Silicon., 2008, 183, 1264.

10. N. Siddiqui, M. Deepanjali, Arshad, A. Rana, Ind J Het Chem., 2007, 16, 403.

11. N. Terzioglu, N. Karali, A. Gursoy, C. Pannecouque, P. Leysen, J. Paeshuyse, J. Neyts, E.D. Clercq, Arkivoc., 2006, 1, 109.

12. (a) M. L. Barrecca, J. Balzarini, A. Chimirri, E. D. Clercq, L. D. Luca, H. S. Hltje, M. Hltje, A. M. Monforte, P. Monforte, C. Pannecouque, A. Rao, M. Zappal, J Med Chem., 2002, 45(24), 5410. (b) M. L. Barreca, A. Chimirri, L. De Luca, A. Monforte, P. Monforte, A. Rao, M. Zappala, J. Balzarini, E. D. Clercq, C. Pannecouquec, M. Witvrouw, Bioorg Med Chem Lett., 2001, 11, 1793. (c) J. Balzarini, B. Orzeszko-Krzesinska, J. K. Maurin, A. Orzeszko, Eur J Med Chem., 2009, 44, 303.

13. (a) N. R. Monks, D. C. Blankey, S. J. East, R. I. Dowell, J. A. Caluete, N. J. Curtin, C. E. Arris, D. R. Newell, Eur. J. Cancer., 2002, 11, 1543; (b) J. B LePez, N. DzXuong, C. Gosse, C. Paolett,. Proc. Natl. Acad. Sci. U.S.A. 1974, 71, 5078.

14. (a) E. S. El-Tamany, F. A. El-Shahed, B. H. Mohamed., J. Serb. Chem. Soc. 1999, 64, 9; (b) Z. H. Ismail; G. M. Aly, M. S. El-Degwi, H. I. Heiba, M. M. Ghorab, Egypt. J. Biotechnol. 2003, $13,73$.

15. M. E. Zaki, H.A. Soliman, O. A. Hiekal, A. E. Rashad, Naturforsch., C 2006, 61, 1.

16. F. Shi. Et. Al., Bioorg. Med. Chem. Lett. 2012, 22, 743.

17. A. B. Bolognese, G. Correale, M. Manfra, A. Lavecchia, E. Novelillo, V. Barone., Org. Biomol. Chem., 2004, 2, 2809.

18. M. A. Martins Alho, N. B. D’Accorso, ARKIVOC, 2011, (vii), 136. 